\title{
O QUASE-TEXTO SOBRE A VISIBILIDADE NA EXPRESSÃO \\ LITERAL
}

\author{
Ione M. G. Bentz
}

RESUMO: This essay reexamines Semiotics under the light of the social practice and communication. Taking the semiotic fact as a communicational one, the notion of conventionality and the factors of contextual and factic order are here considered. The idea of social practice brings up-to-date components of historical, ideological and cultural order, which build up a system of reference where the subject articulates himself. The author expatiates upon the visibility in the literal expression, pointing out the capacities of the languages — since they are signical processes - in order to build up referentials.

PALAVRAS-CHAVE: semiótica, linguagens, código, história, cultura, ideologia, comunicação, visibilidade, enunciados, sujeito.

\section{FORMULANDO COMPREENSÕES}

Considerando que a Semiótica se ocupa dos signos enquanto linguagens, ou seja, sistemas de significação, essas respondem a um recorte teórico que busca uma definição formal para cada classe de função semiótica que se estabelece a partir dos signos, não é relevante estabelecer entre as linguagens diferenças de ordem material. Uma abordagem semiótica situa-se em nível da forma do conteúdo cuja substância corresponde, pela glossemática, à dimensão semântica.

Paralelamente à questão metodológica, há a definição de seu lugar no quadro do conhecimento. Proposta como macrociência — ciência geral dos signos ou, como seu oposto, uma semiose original de dimensões primárias, melhor será considerá-la aqui como uma disciplina cujo projeto está centrado no conjunto da cultura porque se ocupa de coisas reconhecidas como signos que articulados configuram a totalidade da produção humana, ou seja, a Cultura. Assim, nesse primeiro recorte, fica posta a preocupação da Semiótica em definir classes de funções articuladas no universo dos signos. 
A questão da cultura, por sua vez, traz à tona o componente comunicacional da Semiótica, atualizado por Eco, tão mais pertinente quanto se pensar o espaço cultural como interativo e iterativo. A Semiótica fica sendo, portanto, mais do que uma teoria; é uma prática comum cujo sistema semântico estruturável, portanto, dinâmico - só pode ser descrito parcialmente em resposta a acontecimentos comunicativos concretos. Tais acontecimentos nada mais são do que redes complexas de signos que se atualizam a partir de uma semiose primária, ou seja, a relação Expressão (E) e Conteúdo (C), fundadora do signo.

Diga-se, ainda, que sua vocação teórica a impede de considerar a substância que materializa o signo. Logo, o sistema semântico a ser decifrado estaria situado teoricamente no plano da Substância do Conteúdo, a ser abordado pelo plano da Forma do Conteúdo em que seria possível recuperar a cultura não como massa heteróclita, mas como funções sígnicas regulares e identificáveis, portanto, passíveis de análise.

Antes de prosseguir refletindo sobre comunicação e prática social, é preciso recolocar a questão do objeto da semiótica, ou seja, das linguagens. Compreendida como sistemas de signos, ela não faz restrição a qualquer tipo de sistemas de representação, uma vez que se ocupará de todos os signos organizados ou organizáveis sistemicamente. Se teoricamente é possível e desejável distinguir linguagens, espacialmente é irrelevante qualquer proposta de condição. Assumir a incondicionalidade em relação ao processo de semiose é produtivo em termos de investigação, já que equalizando o processo de produção de sentidos - todos resultantes da contratura $\mathrm{E} / \mathrm{C}-$, as atenções devem fixar-se nas diferenças de representação decorrentes da natureza dos sistemas, ou seja, é perfeitamente identificável que o referente construído pelo signo verbal seja distinto daquele construído pelo signo gráfico, por exemplo.

As linguagens podem atualizar-se simultaneamente, imbricando-se em um mesmo tempo e espaço, sem preconceito ou restrição. Ficam postas de lado, em decorrência, questões relativas ao lugar do sistema verbal, por exemplo, sua abrangência e especificidade enquanto ciência. Para a Semiótica, o literal é mais um sistema, dentre tantos ou ao lado da gestualidade, do vestuário, e de outros sistemas similares.

Não se quer com isso descaracterizar o sistema verbal e sua potencialidade representativa decorrente de aspectos de sua natureza como linguagem, qual sejam, a ambigüidade, a convencionalidade implícita, a arbitrariedade e caráter discreto, características responsáveis pelo seu poder de representação e comunicação. O que se considera é que ela se submete ao olhar semiótico como as demais linguagens, simplesmente.

Retomando o fato semiótico como fato comunicacional, é preciso considerar particularmente a convencionalidade do signo. Ele existe com base em correspondência convencionalizada e socializada, não importa com que força construtiva, por que extensão de campo e por quanto tempo. A atualização convencional, por sua vez, atualiza-se no fato comunicacional, ou seja, na inter- 
relação de elementos de emissão/recepção e fatores contextuais e fáticos. Portanto, se interessam os signos atualizados na mensagem, enquanto uma das realizações do sistema, ela não permanece surda às interferências decorrentes do conceito comunicacional. Tal concepção obriga a considerar como elementos teóricos relevantes as inúmeras variáveis reunidas sob o rótulo de circunstâncias de comunicação que circundam os agentes do processo, além das mediações midiáticas tecnológicas.

É preciso recuar para a questão do signo, antes de avançar em direção ao sentido como comunicação que implica comunidade, no dizer de Bakhtin. O deslocamento do conceito mentalista de signo para sua compreensão como de natureza social, abre caminho para uma melhor compreensão da Cultura, essa complexa e escorregadia realidade que se constitui em permanente desafio à Ciência.

Não se trata meramente de justapor ao signo um componente social. Mais do que isso, o social está na base do processo referencial, já que à consciência se atribui esse estatuto. Logo, o que funda o signo é um componente subjetivo (de Sujeito), sustentado por categorias como História, Ideologia e Cultura. A fundação do signo ou a interpretação (enquanto leitura) dos acontecimentos ocorre no quadro dessa referência ampla de articulação do sujeito, por operação de similaridade, representado pela História e pela Cultura, elaboradas por outras referências mais particularizadas, atuantes especificamente sobre o Sujeito e que podem ser reunidas sob o rótulo de Contexto. A ele corresponderão componentes de caráter mais regular, bem como aqueles de natureza contingencial, ocasional, circunstancial. Como elementos de operação de sentido, portanto, estão contexto e circunstância, o primeiro ligado expressamente à comunidade; o segundo à comunicação.

A História é formulada como espaço intertextual, no sentido de que recorrência e redundância levam a reconhecer que o texto produzido representa a totalidade dos textos até então construídos. Como tal, é espaço dinâmico, de construção permanente, mas, ao mesmo tempo, lugar de referência e predicação. A cultura, por sua vez, reúne formas e funções, ou seja, formas sistêmicas que atualizam as funções semióticas e delas decorrem como abstração. As formas comportarão esquemas fixos de representação, tais como regras constitutivas e normativas. Abarcam questões como código, gênero, regras, símbolos, estereótipos, esquemas, classificações, enfim toda a sorte de elementos que se caracterizam por estruturação regular e estável os quais medeiam o processo de significação. As linguagens não deixam de integrar esse quadro, em especial a língua, sistema de inegável prestígio e uso na sociedade dita desenvolvida, como meio preferencial de comunicação. As funções seriam atualizadas pelos enunciados, sintagmas complexos de representação dos significados construídos.

$\mathrm{Na}$ tentativa de visualizar os conceitos operacionais refletidos, tem-se: 
SUJEITO

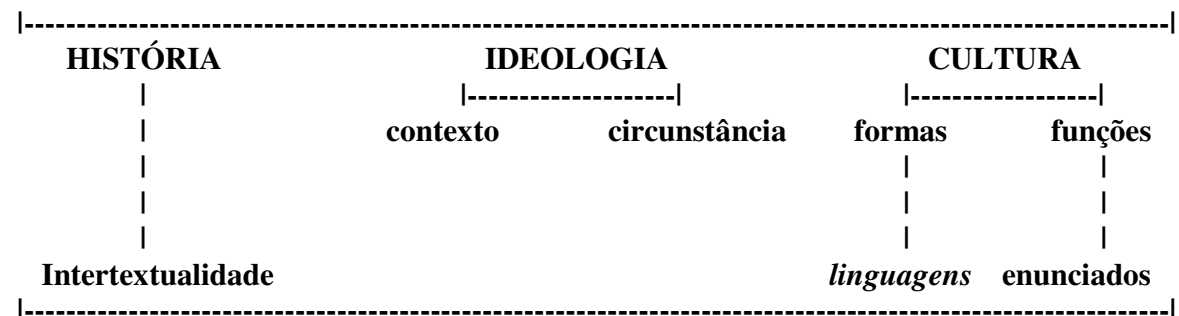

TEXTOS

PROCESSOS DE ENUNCIAÇÃO

Retomando a implicação sentido/comunicação/comunidade, anteriormente aludida, dar-se-á relevância à dicotomia enunciado/ enunciação. Sem necessidade de retornar a Benveniste, esse par de elementos já pode ser considerado princípio consensual de reflexão.

O enunciado é algo mais amplo que mera realização sintagmática abstrata. Esse eixo de contigüidade articula com o paradigma, compreendido como conjunto de possibilidades de contexto de enunciação, a produção dos sentidos. Os elementos paradigmáticos são de natureza social, visualizada pela interação de interlocutores e toda a complexa situação social na qual ela surge. As linguagens não pertencem ao indivíduo, mas a seu grupo social; socializam-se a si e a sua ação. Os enunciados como a experiência exprimível são de natureza social. O enunciado como presença material do discurso e o sentido por ele veiculado tem como elemento mediador o sistema de valores da sociedade, capaz de unir a singularidade do enunciado com a generalidade de seu sentido. Nessa perspectiva, o enunciado fica irremediavelmente preso às condições reais de enunciação.

Assim se prenuncia a diferença entre significação nas linguagens e no discurso. Nas linguagens, opera-se com o nível dos possíveis; no discurso, enquadra-se o enunciado com base em situações históricas concretas. Casam-se as formas com os aspectos contextuais e circunstanciais das funções. Os enunciados configuram-se como unidades concretas no horizonte ideológico.

Os enunciados, compreendidos desse modo, articulam textos que se encontram nos limites ou na interação entre o verbal e o não-verbal, entre o dito e o não-dito. Atente-se em especial para o não-dito, primeiro porque representa espaço aberto de construção sígnica; segundo porque, à revelia das formas, ou até delas decorrente, opera como índices de sentidos propostos. Resgata-se como elemento teórico uma zona de extrema relevância para o sentido - a do implícito situando-a no mesmo plano do explícito. Ainda mais: consegue-se compreender o implícito e o explícito como auto-referenciantes reciprocamente.

A construção de enunciados como realidade discursiva pressupõe operação, agentividade: sujeito. Tais sujeitos entram em relação dialógica, do mesmo modo que todo enunciado reporta-se também a enunciados anteriores, 198 
dando lugar a relações intertextuais. O processo dialógico é, portanto, de natureza semiótica e comunicacional. Pela proposta de Bakhtine, ao cotejar--se com as funções de Jakobson, a dialogia intertextual seria de natureza fática. Em sentido largo, a dialogia expressa-se em diferentes níveis, como, por exemplo, naquilo que neste trabalho se chamou História. A dialogia, portanto, funda e atualiza, simultaneamente os espaços significativos.

\section{FALANDO DE TEXTOS}

— Isto é um assalto, perua. Vai passando o relógio!!

— De novo!! É o quarto relógio que me levam em um mês! Até relógio do Mickey já me roubaram!! É uma invasão, uma violência no meu direito de saber as horas, e de usar o que eu quero no pulso!

— Tudo bem! Tudo bem! Toma de volta! Eu só quero faturar uns trocados...

- Nem pensar! Não quero emperrar o processo de confronto social e também não aceito trocados de volta!!

O texto acima, publicado no jornal Folha de São Paulo em 10/04/94, é de Miguel Paiva. Radical Chic é um texto em que a linguagem verbal e icônica interagem. Em estudo anterior ${ }^{1}$ ficou evidente a independência da linguagem verbal em relação à imagem, princípio que legitima isolar os enunciados verbais com o intento de não só apontar os elementos constitutivos do processo de enunciação, tal como foi proposto no âmbito deste trabalho, mas de oferecer condições de compreender a visibilidade construída pelo literal.

$\mathrm{O}$ tema teórico visibilidade na expressão literal, que aqui se registra, inspira-se no trabalho Seis propostas para o próximo milênio de Calvino em que ele discorre sobre os tópicos que deverão marcar o próximo século: leveza, exatidão, multiplicidade e visibilidade.

Opondo a leveza ao peso do viver, concede-a apenas à inteligência em sua vivacidade e mobilidade. Impossível, encontrá-la na vida, essa "intrincada rede de construções públicas e privadas" que aprisionam "cada existência em suas malhas cada vez mais cerradas".

O que se diz é que a leveza só poderá ser encontrada no mundo dos significados construídos. Dicotomizando a linguagem factual e linguagem do relato, seria possível por essa primeira semiose promover o apagamento de vida concreta, indelevelmente pesada, em favor da leveza do sentido. O sentido é sempre leve porque não se confunde com a materialidade sensível do acontecimento. Todo o peso que a linguagem verbal puder desencadear a partir da construção do sentido, estará sempre no plano sígnico e, portanto, estruturável em novas significações.

Se é verdade o que se diz das operações significativas, as imagens do

\footnotetext{
${ }^{1}$ BENTZ, I. A dêixis em Happy Days. (inédito).
} 
mundo correspondem à concepção do homem, considerados os limites do desejo no quadro das instituições culturais codificadas. $\mathrm{O}$ homem produz sentidos nos limites de sua biologia e de sua história. O desejo, se assim se quiser chamar, situa-se na verticalidade, paradigma de suas potencialidades; a história, sincrônica e atualizadora, processa a rede complexa de relações que se atualiza na relação Homem e Cultura, Necessidade e Circunstância.

Em síntese, as palavras não são as coisas. É o que Calvino também diz quando reconhece que $o$

peso da matéria se dissolve pelo fato de poderem ser numerosos e intercambiáveis os materiais do simulacro humano; a metáfora não impõe um objeto sólido e nem mesmo a palavra pedra chega a tomar pesado o verso.

O processo de significação seria sempre a possibilidade de apagamento de uma dada referência, ou seja, a materialização da função poética da linguagem, no sentido que lhe confere Jakobson.

A rapidez, vista sob o mesmo ângulo interpretativo com que se viu a leveza, ganha interesse porque opera a categoria do tempo enquanto velocidade e possibilidade homogeneizadora. Alia-se à visibilidade em sua capacidade de desenvolver potencialidades implícitas e formar campos de analogias, simetrias e contraposições. Por um processo de abstração, interioriza-se a experiência sensível e visualiza-se, por verbalização, o pensamento. A matéria verbal constrói visões polimórficas, encadeadas pela presença simultânea dos elementos os mais heterogêneos que se multiplicam iterativamente, como interpretantes da cadeia peirciana. Os enunciados desdobram-se em todas as direções, uma vez que qualquer totalidade não pode ser compreendida senão como potencial, conjetural e multíplice. O texto não é unitário, não é discurso de uma única voz. Os enunciados múltiplos substituem a unicidade de um eu pela multiplicidade de sujeitos e vozes, respondendo à estrutura dialógica da linguagem.

É, na verdade, o que realizam textos como:

Sou o ser que vê,

E vê tudo estranho

[...]

Tudo é ilusão

Sonhar é sabê-lo

(O.P., p.142).

Ao longe o luar,

No rio uma vela,

Serena a passar,

Que é que me revela?

Não sei, mas meu ser

Tomou-se-me estranho,

E eu sonho sem ver

Os sonhos que tenho 
Que angústia me enlaça?

Que amor não se explica?

É a vela que passa

$\mathrm{Na}$ noite que fica.

(O.P., p.143).

Ou textos como:

Sempre que o programa vai ao ar, a audiência vai ao chão

(Veja, p.25).

Há um ano, o brasileiro fechou o verão patinando no gelo do plebiscito

(Veja, p.25).

O sistema segue vil como sempre

(Veja, p.28).

As considerações feitas acerca da natureza da linguagem e do processo de construção dos sentidos permitem reduzir a uma só totalidade produções de diferentes estatutos, como as acima transcritas, com a intenção de evidenciar a potencialidade do verbal em suas relações com o tempo, a forma e o movimento. Equalizam-se, por outro lado, os discursos pela presença neles dos componentes do processo de enunciação.

Mais especificamente, no texto de Miguel Paiva, as informações textuais levam a reconstruir a História que, enquanto intertextualidade, dá a conhecer o tipo de texto que se quer identificar: o diálogo. A Ideologia é reconstruída pelos elementos de contexto-ação — reiteração da ação, caracterização dos actantes, articulação das seqüências narrativas - e de circunstância, como a performatividade, a imprevisivilidade, a cooptação. Tais categorias mais generalizantes organizam-se a partir de elementos menores construídos pelo sentido, até institucionalizado, que é conferido a lexemas como perua, roubo, Mickey, violência, direito, trocados, confronto social entre outros, além dos elementos implícitos nos enunciados atualizados. A articulação textual organiza os componentes verbais de modo a constituir um espaço semiótico articulado.

\section{BIBLIOGRAFIA}

BENTZ, I. A dêixis em Happy Days. (inédito).

CALVINO, Ítalo. Seis propostas para o próximo milênio. São Paulo, Companhia das Letras, 1990.

ECO, Umberto. Tratado geral de semiótica. São Paulo, Perspectiva, 1980.

GALHOZ, M. A. (Org). Obra poética. Rio de Janeiro, Aguilar, 1965.

JAKOBSON, R. Lingüística e comunicação. São Paulo, Cultrix, 1974.

TODOROV, T; BAKHTINE, Mikhail. Le principe dialogique. Paris, Seuil, 1981.

VEJA, v.27, n.12, 23 mar. 1994. 
